\title{
ArtsSciences Design-a-thon: Solving Complex Problems in Interdisciplinary Teams
}

\author{
Melissa Bremmer ${ }^{1 *}$, Emiel Heijnen ${ }^{1}$, Anna Hotze ${ }^{2}$, Monique Pijls ${ }^{3}$, Emer Beamer ${ }^{4}$, Nathalie Roos ${ }^{1}$ \\ 1 Amsterdam University of the Arts, NETHERLANDS \\ ${ }^{2}$ University of Applied Sciences iPabo, NETHERLANDS \\ ${ }^{3}$ Amsterdam University of Applied Sciences, NETHERLANDS \\ ${ }^{4}$ Design-a-thon Works Foundation, NETHERLANDS
}

*Corresponding Author: melissa.bremmer@ahk.nl

Citation: Bremmer, M., Heijnen, E., Hotze, A., Pijls, M., Beamer, E. and Roos, N. (2021). ArtsSciences Design-a-thon: Solving Complex Problems in Interdisciplinary Teams. European Journal of STEM Education, 6(1), 11. https://doi.org/10.20897/ejsteme/11342

Published: November 11, 2021

\begin{abstract}
In this empirical study, the one-day project Robot Love Design-a-thon was designed for an interdisciplinary group of preservice teachers (in arts, sciences, and primary education), and evaluated through observations and learner reports. An analysis of the observations and the learner reports showed that having to go through a complete design process in a single day worked well: it facilitated the exchange of ideas and critical discussions between students concerning the project's socially engaged theme 'Tenderness and Technology'. In addition, interdisciplinary collaboration emerged as an important learning outcome. All students found working in mixed teams a relevant and educational experience as they could profit from each other's expertise.
\end{abstract}

Keywords: interdisciplinary education, STEAM-education, ArtsSciences, Design-a-thon, preservice teachers

\section{INTRODUCTION}

To solve complex cultural, technological, economical, ecological, and political challenges, there is a growing need for highly qualified professionals who can look beyond disciplines and excel in 21st-Century Skills such as critical thinking, problem-solving, cooperation, and creativity (Davies and Devlin, 2010; Ministry of Education, Culture \& Science, 2015). This need for a new type of professional has increased the interest of higher education in interdisciplinary education (Berganton, 2017; Newell, 2009). Traditionally, higher education has focused on teaching disciplines with their own theories, methods, and contents (Squires, 1992). Davies and Devlin (2010) note that the term discipline is used to describe a discrete area of study, normally not cooperating or coordinating its academic effort across disciplinary boundaries. Yet, a comprehensive understanding of a complex societal problem is often facilitated by a cross-disciplinary approach because complex problems related to societal issues like digitalization, climate change, and health touch on a manifold of disciplines (De Greef, Post, Vink and Wenting, 2017; Newell, 2007). Hence, interdisciplinary courses can offer students opportunities to develop an understanding of a problem 'through the integration or derivation of different concepts, methods and epistemologies from different disciplines in a novel way' (Rogers, Scaife and Rizzo, 2005, p. 3).

A particular form of interdisciplinary practice that is of interest for the development of a new type of professional is found in contemporary hybrid arts and sciences practices. These practices raise questions at the 
intersection of the arts and sciences and combine non-traditional ways of researching, such as design research, speculative design, and critical making with more established ones to explore complex problems (Gabrys and Yusoff, 2012; Miller, 2014). Root-Bernstein, Siler, Brown, and Snelson (2011) coined the term ArtScience to describe these types of practices. In this article we have changed that term to the plural ArtsSciences to indicate the many arts and sciences that can be drawn on. Through courses based on these ArtsSciences practices, students in higher education learn to blend different forms of expertise, theories, and methodologies, that can lead to innovative and thought-provoking insights into societal issues (De Greef, et al., 2017; Zwijnenberg, 2013).

Although these courses are relevant to many students, they are specifically relevant to preservice teachers due to the internationally emerging paradigm of STEAM-education, which evolved from STEM-education (Hogenes, Diepenbroek, Bremmer and Hoogerheide, 2021). STEAM-education integrates science, technology, engineering, arts, and mathematics in primary and secondary education, and often anchors its pedagogy in Inquiry- and Designbased Learning (Liao, 2016; Sanders, 2009). Due to its interdisciplinary nature, its novel pedagogical approach and focus on societal problems, STEAM is regarded as a fruitful way to develop the 21st-century skills of pupils. Currently, as an alternative to the acronym STEAM, the term ArtsSciences-education is emerging in the Netherlands (Heijnen and Bremmer, 2019).

Before teaching any type of education that integrates arts and sciences, preservice teachers should be familiarized with its pedagogical strategies (Lam and Chan, 2011), learn to cooperate with teachers from different disciplines (Hotze et al., 2019), learn to cross the border of their discipline (Akkerman and Bakker, 2011), and learn to develop a communal language with teachers in other disciplines (Wilschut and Pijls, 2018).

To aid preservice teachers in developing knowledge and skills needed to design and teach any form of integrated ArtsSciences education, the platform Education at the Intersection of Arts, Science and Technology initiated the interdisciplinary, one-day project Robot Love Design-a-thon. This project was designed integrally for preservice art teachers, preservice science teachers, and preservice primary education teachers. It aimed to provide them with the experience of working on a complex ArtsSciences problem in interdisciplinary teams and through Inquiry-and Design-based Learning, so they would be able to apply this in primary or secondary education. The goal of the accompanying research study was to evaluate the Robot Love Design-a-thon and to gain insight into the interdisciplinary working process of the preservice teachers, their learning outcomes, and the pedagogical approach of the supervisors.

In this article, we will first take a closer look at the strengths of ArtsSciences-education. We will also describe how Design-a-thon, a pedagogical approach within ArtsSciences-education, was translated to the project Robot Love Design-a-thon. Furthermore, the research methodology for evaluating the project and the findings that could lead to the improvement of such ArtsSciences projects will be discussed.

\section{ARTSSCIENCES IN EDUCATION}

ArtsSciences-education is a specific form of interdisciplinary education in primary and secondary schools, with its own unique strengths. First of all, it could be considered a strength that pupils learn to critically solve problems in a 'bands-on' way through Inquiry- and Design-based Learning. 'Critically' is traditionally associated with critical thinking: an abstract, linguistic, and internal activity (Heijnen and Bremmer, 2019). Ratto (2011) observes, however, that one can critically think through the process of making - and therefore talks about 'critical making'. By producing and assessing, generating, and judging designs, pupils can be stimulated to make/think critically in and about the world (Quigley and Herro, 2016). Moreover, pupils can enter a critical making process with tools and technologies stemming both from the arts and sciences (Bogers and Chiappini, 2019).

Secondly, education plays an important role in preparing pupils for the challenges in future societies (Groenendijk and Heijnen, 2018). In this context, schools need to address the development of 21st-century skills such as problem solving, creativity, technology literacy, and cooperation, as these will enable pupils to positively contribute to a globalized and ever-changing society (Heijnen, Bremmer, Koelink and Groenendijk, 2020; Hogenes et al., 2021). Research studies demonstrate that when pupils learn these types of skills in isolated school subjects, they find it difficult to transfer them to different domains (Pellegrino and Hilton, 2012; Van Merriënboer, 2013). However, we assume that by integrating arts and sciences in curricula, pupils will not only have the opportunity to develop those 21 st-century skills, but also to apply them across subjects more easily than when learned in isolated subjects (Marshall, 2014).

Lastly, an asset of ArtsSciences-education is that it can be based on existing professional ArtsSciences practices, such as the architectural human rights investigators of Forensic Architecture or the research of spider webs by Studio Tomás Saraceno. These practices can provide educators with insights into which themes, materials, and working processes are pivotal in ArtsSciences (Heijnen, 2015). 


\section{DESIGN-A-THON}

A compact pedagogical strategy suited to teaching ArtsSciences-education is the Design-a-thon method. The Design-a-thon method was originally developed for primary education by Emer Beamer in 2014 and combines elements of Design Thinking, Inquiry- and Design-based Learning, and Maker-education (Beamer Cronin and Hyman, 2018). In general, Design Thinking and Inquiry- and Design-based Learning are based on how scientists and designers approach problems in real-life settings (Kraaij, 2015). The Design-a-thon method consists of a structured workshop facilitated by education professionals of the foundation Design-a-thon Works, in which pupils invent, build and present their solutions to a social or environmental problem (Beamer, 2017). The workshops can last two to six hours, are structured through works sheets and provided with a Maker-kit containing, amongst others, motors, led lights, switches, ventilators, alarms, and wheels (Beamer Cronin and Hyman, 2018). The Design-a-thon workshops all follow the same design cycle as demonstrated in Figure 1.

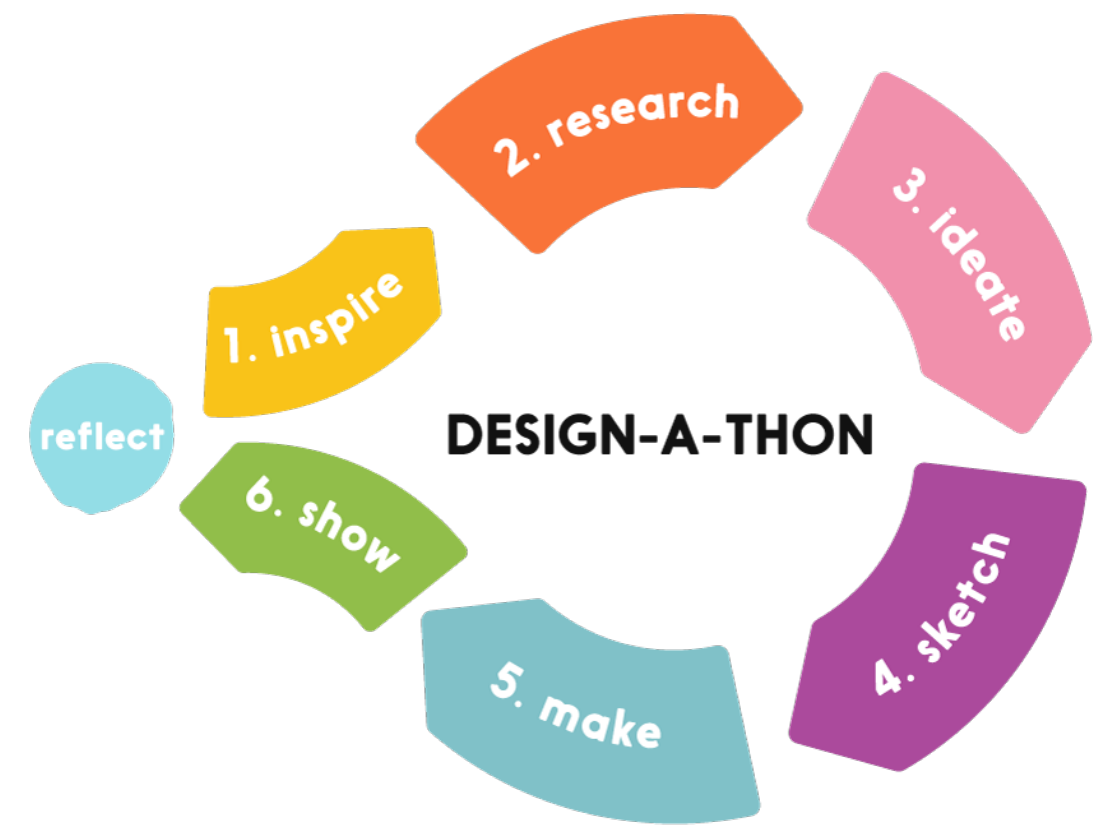

Figure 1. Phases of the Design-a-thon method (Beamer, 2017)

In the phase of 'Inspire' a societal or environmental theme, such as waste, mobility, food, or water is introduced to inspire and to invite pupils to (philosophically) discuss problems within that theme. In the phases 'Research' and 'Ideate' pupils investigate problems within the offered theme and choose a problem they want to work on. In the 'Sketch'-phase, pupils visualize ideas to solve the problem (design concept), and in the 'Make'-phase they transform a design concept into a prototype with materials, amongst others, from the Maker Kit. In the phase of 'Show' and 'Reflect' pupils present their prototypes to each other and reflect on the design process and the prototype.

\section{ROBOT LOVE DESIGN-A-THON}

Together with the educational professional of Design-a-thon Works, the researchers translated the Design-athon method to the context of higher education. First of all, a meaningful environment was chosen for the preservice teachers' Design-a-thon: the provocative exhibition Robot Love in Eindhoven, the Netherlands. The exhibition explored how we can accept - or even love - robots. The artists Lancel \& Maat, whose work intersects at arts, science, and technology, were asked to introduce the exhibition's theme and to give a tour through the exhibition that included their work. Secondly, a real-life problem relating to the exhibition was presented to the preservice teachers: 'How can technology promote tenderness between people'? The preservice arts, science, and primary education teachers had to investigate and critically discuss this problem in interdisciplinary teams, whilst being supervised by the artists and a supervisor from Design-a-thon Works. Lastly, based on their design concepts, the preservice teachers had to develop prototypes, using a combination of low-tech (e.g., sensors, leds) and other materials (e.g., paper, clay, rope). During the testing phase, they discussed their prototypes with their peers, the artists, and supervisor, asking for their critical feedback to improve their prototypes. The Design-a-thon ended with a presentation of all the prototypes. 


\section{METHODOLOGY}

\section{Research Questions and Research Design}

To date, empirical research exploring ArtsSciences projects for preservice teachers in higher education is scarce (Hotze et al., 2019). This study, therefore, aimed to collect data that shed a light on how the design and execution of similar projects might be improved. Consequently, the research questions were:

- How does the interdisciplinary working process of preservice teachers develop during the Robot Love Design-a-thon?

- What kind of feedback (process- or product-orientated) do the supervisors provide during the design process of the preservice teachers?

- What are the perceived learning experiences and outcomes of the preservice art, science, and primary education teachers regarding the Robot Love Design-a-thon?

An evaluation research was chosen to answer these questions. The purpose of this type of research is to evaluate the impact of an (educational) intervention (Powell, 2006). The results of such research are then used to modify or adapt a programme to enhance its success (Powell, 2006).

\section{Participants}

Next to the artists Lancel \& Maat and a supervisor from Design-a-thon Works, nineteen preservice teachers of four Universities of Applied Sciences in the Netherlands took part in the Design-a-thon (see Table 1). The preservice teachers were placed into five interdisciplinary teams.

Table 1. Preservice teachers participating in Design-a-thon

\begin{tabular}{lll}
\hline University of Applied Sciences iPabo & primary education teachers & 3 \\
\hline Amsterdam University of the Arts & art teachers & 13 \\
\hline Fontys University of Applied Sciences & science teachers & 2 \\
\hline Teacher College Windesheim & science teacher & 1 \\
\hline
\end{tabular}

\section{Research Methods}

Two research methods were applied in this evaluation study. First of all, a non-participant, structured observation was used: each interdisciplinary team was observed by a researcher throughout the different phases of the Design-a-thon. As an observation tool, a spreadsheet was used containing the following three themes:

1. The role the different preservice teachers take on during the different phases of the Design-a-thon (problem solver, mediator, critic, initiator, listener, leader, or other);

2. The expertise different preservice teachers contribute during the different phases of the Design-a-thon (art, science, educational, or other expertise);

3. The way the supervisors guide the preservice teachers (product-oriented guidance and/or process-oriented guidance).

Secondly, a learner report was used: an open self-evaluation method allowing learners to describe what they learned or how they experienced an educational project or curriculum (De Groot, 1980). In this study, the open format of a learner report enabled the preservice teachers to report unexpected or unintended learning outcomes too (Van Kesteren, 1993). They filled out the learner reports anonymously immediately after the Design-a-thon. They answered the following three questions:

1. What did you learn or experience during the Design-a-thon?

2. What have you learned that is different to what you thought you would learn, or that did not work for you, or was not true?

3. What appealed to you the most or least regarding the Design-a-thon?

Each question gave examples of how the questions could be answered such as: 'I experienced', 'I noticed', or 'I learned that it is not true that...'

\section{Data Analysis}

The data of the observation tool was used to create a narrative of the design process of the teams, describing (1) the interdisciplinary working process and (2) the roles the preservice teachers took on, the expertise they exhibited, and (3) the way the artists and supervisor guided the preservice teachers. In this study, the narratives of two teams are presented (both composed of a preservice primary education teacher, two preservice art teachers, and a preservice science teacher) that were chosen on the basis of the selection criterium 'maximum variation cases' (Flyvbjerg, 2006). 
Regarding the data of the learner reports: all statements of the preservice teachers were first placed into a spreadsheet. Afterwards, thematic coding was applied to analyse the data (Braun and Clarke, 2006). This meant that the statements were first coded deductively by two researchers with the following three themes: 'method Design-a-thon', 'interdisciplinary working process', and 'meaningful learning environment' (with a focus on the theme of the exhibition and the exhibited artworks).

During the thematic coding process, the researchers were open to new themes that could be found in the data. For instance, within questions 1 and 2 (What did you learn/experience?) 'technology' was found as an additional theme. Within question 3 (What appealed to you the most/least?) the theme 'curriculum materials' was found, and within the theme interdisciplinary working process a distinction could be made between the general working process and the composition of the team.

A third researcher re-coded all the statements with the developed codes. In the case of differences between researchers, a theme was chosen for the data on the basis of consensus. See Table 2 for an overview of the themes that were used for analysis.

Table 2. Overview themes for analysis

\begin{tabular}{|c|c|}
\hline $\begin{array}{l}\text { Question: } \\
\text { 1. What did you learn or experience during the Design-a- } \\
\text { thon? } \\
\text { 2. What have you learned that is different to what you } \\
\text { thought you would learn, or that did not work for you, or } \\
\text { was not true? }\end{array}$ & $\begin{array}{l}\text { - Method Design-a-thon } \\
\text { - Interdisciplinary working process } \\
\text { - Meaningful learning environment (theme of exhibition, the artworks) } \\
\text { - Technology } \\
\text { - } \text { Other }\end{array}$ \\
\hline $\begin{array}{l}\text { Question: } \\
3 \text { What appealed to you the most or least regarding the } \\
\text { Design-a-thon? }\end{array}$ & $\begin{array}{l}\text { - Method Design-a-thon } \\
\text { - Interdisciplinary working process: in general } \\
\text { - Interdisciplinary working process: the composition of the team } \\
\text { - } \text { Meaningful learning environment (theme of exhibition, the artworks) } \\
\text { - } \text { Curriculum materials } \\
\text { - Other }\end{array}$ \\
\hline
\end{tabular}

\section{FINDINGS}

\section{Observations of Team One}

Interdisciplinary working process: Based on the provided worksheets, the team members first started exploring the problem 'How can technology promote tenderness between people'. In the first hour, hardly any concrete ideas or solutions for the problem were discussed, and the team got stuck on the premise that it wanted to translate the solution to education. After one of the supervising artists made a concrete suggestion to the team (a robot who teaches children about tenderness), the process of brainstorming commenced. During this process, the idea of the artist was turned around: children who teach a robot about tenderness. Partly inspired by works from the exhibition, the team agreed that they should not design a mechanical robot, but somehow a 'soft robot'. It was striking that the phase of ideation was mainly driven by the exchange of preferences concerning shapes and materials for this 'soft robot'. The team experimented with the Maker Kit materials, but in the end the preservice art teachers preferred to stick to their design concept, because they found the materials 'too unattractive'. Meanwhile, the design concept had become more concrete: pupils who teach an interactive bean bag about tenderness via an interface. During the show phase the concept of the beanbag was deepened through three feedback rounds and the final presentation of the team was a convincing one.

Roles: This team consisted of two clear leaders. The preservice science teacher who structured the discussions and kept an eye on the planning, and one of the preservice art teachers who mainly played a pioneering role in terms of the content of the design concept. At key moments, this preservice teacher provided the ideas that were elaborated on by the team: turning around the idea of the artist (children teach a robot) and the idea of the beanbag. The other two preservice teachers did remain involved in the design process. The preservice primary education teacher kept notes of the discussions and, for example, questioned the design concepts during the research phase. The other preservice art teacher was cooperative and tried to connect ideas that arose in the discussions. In the ideate phase everyone contributed ideas, but these were mainly given more depth by the two leaders. The preservice science teacher focused mainly on the technical possibilities of the beanbag, bringing in some domain-specific knowledge about programming. The preservice art teacher was increasingly able to substantiate the design concept. She noted: 'At this age, touch and tenderness are quite a thing [for pupils]. Such a furry, sweet beanbag is more accessible to pupils than a real person.'

Supervision: The feedback of the supervisor of Design-a-thon Works was mainly process-oriented (e.g. how are you getting along with the worksheets?). Despite her feedback, the team initially got stuck in the design process. This changed after one of the artists provided product-oriented feedback. Her concrete proposal about a robot 
teaching children about tenderness, gave the team's creative process a boost. After developing a design concept, the supervisor of Design-a-thon Works encouraged the team to start making 'something'. However, the team continued to focus strongly on the conceptual aspects of their design during the make phase, instead of actually making a prototype of the concept. This reluctance seemed to be related to the resistance that the preservice art teachers felt towards the offered materials.

\section{Observations of Team Two}

Interdisciplinary working process: during the design process, the preservice teachers started by completing the worksheets and by having a broad conversation about the exhibition, their previous experiences with 'making' and technology, and whether or not a robot could actually be human. Then they discussed different ideas about robots in relation to tenderness and one of the preservice art teachers critically questioned the design problem: 'What if a robot is not functional? I think it could be funny when robots are just very dysfunctional.' These comments ended a further conversation on 'tenderness' in relation to robots and the team decided to focus on a robot that could cheer people up or on a robot that could help autistic children to make contact. The team gave little attention to visualizing their design concept, but at some point started building a robot from Lego. The peer feedback rounds helped to create a narrative for this prototype robot. In the presentation phase, the team presented a robot that could function as an interface between grandparents and their grandchildren: the robot should be programmed to make suggestions to the grandparents about which questions they could ask their grandchildren.

Roles: During the inspire phase of the Design-a-thon, the four preservice teachers contributed to the discussion about the theme 'technology and tenderness'. Two preservice teachers, however, seemed to be especially taskoriented: the preservice primary education teacher took the lead in the discussion and moderated it, and the preservice science teacher initiated and read the assignments, collected materials and cleaned them up. During the research phase, the two preservice art teachers took a highly critical stance and kept trying to change the proposed design concepts. The preservice primary education teacher tried to make a connection to education. 'Oh yes, [we could design] a robot with humour, for example for autistic children at school'. However, the preservice art teachers did not really want to integrate technology into the design concept. At one point, the two preservice art teachers more or less withdrew from the collective design process and commenced with the making phase by building a robot with Lego. The preservice science teacher used electronics to build a light for the robot. During the peer feedback rounds, it was mainly the preservice primary education teacher who discussed their design concept and started providing the robot with a narrative.

Supervision: The supervisor of Design-a-thon Works started off with providing process feedback: "Are you going to get started [with the worksheets]?' When one of the artists came by during the ideate phase, the preservice teachers presented their preliminary design concepts: 'a kind of robot that makes people happy' and 'a robot for children with autism'. Subsequently, the artist elaborated on those concepts and also reacted critically: 'I think it's two different things: a robot that makes contact - a lot of research has been done into robots and autism, or a robot that provides you with humour to cope with a difficult situation'. The artist's critical comments were perceived by the team as a 'negative assessment' of their concepts. Afterwards, the design process seemed stifled and the team struggled with their design concept. The peer feedback and the fact that they had to present their design concept to peers, however, helped to sharpen the design concept and to develop its narrative.

\section{Learner Reports}

Straight after the Design-a-thon, the preservice teachers completed a learner report. Table 3 presents the different themes through which the statements of question 1 and 2 were coded, gives an example of such a statement, and the number of statements per theme.

Table 3. Themes, examples of statements, and number of statements per theme regarding the questions: 1 . What did you learn or experience during the Design-a-thon? And 2. What have you learned that is different to what you thought you would learn, or that did not work for you, or was not true?

\begin{tabular}{ll}
\hline Theme & Example statement \\
\hline Method Design-a-thon & $\begin{array}{l}\text { 'I have discovered that you can design a concept in a relatively short time, I had not } \\
\text { expected that this was possible' }\end{array}$ \\
\hline Interdisciplinary working process & $\begin{array}{l}\text { 'I have discovered that working with unknown preservice teachers stimulates you in a } \\
\text { different way' }\end{array}$ \\
\hline $\begin{array}{ll}\text { Meaningful learning environment } \\
\text { (theme of exhibition, the artworks) }\end{array}$ & $\begin{array}{c}\text { 'I experienced how art and robotica influence each other or go together' } \\
\text { Technology }\end{array}$ \\
\hline $\begin{array}{l}\text { Other } \\
\text { 'I noticed it's also possible to use technology in an accessible way so that everyone }\end{array}$ \\
\hline
\end{tabular}


The largest number of statements were made within the theme Method Design-a-thon, where preservice teachers indicated that they had learned a lot about this method. They particularly mentioned that experiencing a complete design process in a short period of time (one day) worked well: it facilitated their exchange of ideas and critical discussions about technology and tenderness. A primary education preservice teacher stressed the practical application of this method: 'I have learned that I can also do this in my classroom.' Also within the theme Interdisciplinary working process, all preservice teachers were unanimous: collaborating with preservice teachers from other disciplines was valuable and working with different ages was noted as a positive experience.

Within the theme Meaningful learning environment participants differed in opinion: preservice art teachers indicated that they found the exhibition inspiring and described their gained insights into tenderness and robotics. On the other hand, for preservice teachers without an art background, the exhibition was a less appealing experience: 'I found the exhibition was not what I expected it to be.' Within the theme Technology, it was striking that all the coded statements came from preservice art teachers. Many of them were surprised that the technology could be accessible and easy to apply.

Table 4 presents the different themes through which the statements of question 3 (concerning what appealed the most / least to the preservice teachers) were coded, gives an example of such a statement and the number of statements per theme.

Table 4. Themes, examples of statements and number of statements per theme regarding question 3 What appealed to you the most or least regarding the Design-a-thon?

\begin{tabular}{llcc}
\hline Theme & Example statement & $\begin{array}{c}\text { Frequency } \\
\text { positive }\end{array}$ & $\begin{array}{c}\text { Frequency } \\
\text { negative }\end{array}$ \\
\hline Method Design-a-thon & $\begin{array}{l}\text { Positive: 'That we were guided through the design process by means of } \\
\text { worksheets' } \\
\text { Negative: 'The distinct large amount of childish worksheets' }\end{array}$ & 11 & 18 \\
\hline $\begin{array}{l}\text { Interdisciplinary working process: } \\
\text { in general }\end{array}$ & Positive: 'Sharing ideas' & 4 & 0 \\
\hline $\begin{array}{l}\text { Interdisciplinary working process: } \\
\text { team composition }\end{array}$ & Positive: 'The diversity of the group in background and age' & 11 & 3 \\
\hline $\begin{array}{l}\text { Meaningful learning environment } \\
\text { theme of exhibition, the artworks) }\end{array}$ & $\begin{array}{l}\text { Positve: The exhibition was very interesting and I wouldn’t have wanted to } \\
\text { Negative: 'I found the exhibition rather disappointing because nearly } \\
\text { everything was just to look at. I expected more profundity' }\end{array}$ & 14 \\
\hline Curriculum materials & $\begin{array}{l}\text { Negative: 'T expected there to be real robotization, technology and } \\
\text { knowledge to implement or do' }\end{array}$ & 1 \\
\hline
\end{tabular}

Most of the statements (29) related to question 3 could be connected to the theme Method Design-a-thon and showed a mixed picture. On the one hand, there were preservice teachers who appreciated the worksheets and working according to the set phases of the Design-a-thon method. Participants were also positive about the freedom they were given in exploring the theme, about brainstorming about their design concept, and developing a design concept. On the other hand, other preservice teachers were negative about having to systematically work through the design phases, and felt the worksheets were too structured: 'sometimes it came across as schoolish, in terms of filling in worksheets, and working in a structured way.' The preservice art teachers predominantly made negative statements in this theme (13 statements negative against 5 positive).

Four statements could be assigned to the theme Interdisciplinary working process (in general), all from science preservice teachers, except for one art preservice teacher. They appreciated the exchange of ideas and how well the team collaborated. Within the theme Interdisciplinary working process (team composition), art and primary education teachers were positive about working with different disciplines and ages. Criticism concerned the imbalance between disciplines within the teams: preservice art teachers felt it was especially a pity that so few preservice science teachers had taken part.

The statements in the theme Meaningful learning environment (theme of exhibition, the artworks) made clear that the exhibition and the theme mainly appealed to the preservice art teachers (13 out of 17 statements). Within the theme Curriculum materials it was striking that practically all statements were negative (11 negative, 1 positive). Ten of the negative statements were made by preservice art teachers, who indicated that they had expected more technology, and found the curriculum materials too simple or childish. 


\section{DISCUSSION AND CONCLUSION}

In this evaluation study we set out to explore the preservice teachers' experiences with the design and execution of the Robot Love Design-a-thon.

Concerning the interdisciplinary working process, the findings showed that the Design-a-thon challenged the preservice teachers to exchange ideas and to critically discuss the theme 'technology and tenderness' during the whole design process. Thus, the starting point of the Robot Love Design-a-thon that preservice teachers should critically discuss a societal theme on the intersection of arts, science, and technology was achieved. Furthermore, due to the diverse disciplines in a team, different perspectives could be given on the theme, thereby deepening or broadening discussions (Gess, 2017). The prototypes used to visualize the solutions of the problem, ended up being rather basic. However, they were functional for explaining and critically discussing the design concepts and the innovative ideas underlying them. Finally, although seen by some as a positive aspect, other preservice teachers were negative about the structured approach of the Design-a-thon method, even though it did seem to bring focus in the design process.

Regarding the supervision, our observations showed the supervisor of Design-a-thon primarily giving processorientated feedback and the artists critical product-orientated feedback. Interestingly, these two sorts of feedback seemed to be experienced both positively as negatively by the preservice teachers. Therefore, providing a combination would seem a preferred strategy: process-orientated feedback gives preservice teachers agency in developing a design concept but without product-orientated feedback the concepts might remain superficial. On the other hand, product-orientated feedback can push the creative design process forward but can be experienced as too directive, leaving too little space for personal interpretations and ideas.

Concerning the perceived learning experiences and outcomes, the findings demonstrated that the preservice teachers had learned how the Design-a-thon method works in practice and about the content of the theme 'technology and tenderness'. Research studies demonstrate that, if (prospective) teachers do not have any experience with a certain teaching method, such as for instance the Design-a-thon, they may feel apprehensive about its implementation (Van Casteren, Van den Broek, Hölsgens and Warps, 2014). On the other hand, (prospective) teachers who experience cross-curricular education themselves tend to apply this more often in their classroom (Kim and Bolger, 2017; Rinke, Gladstone-Brown, Kinlaw and Cappiello, 2016). By taking part in the Design-a-thon, the preservice teachers in this study were given concrete tools for cross-curricular education, enhancing the likelihood of applying it in their own classroom (Lam and Chan, 2011; Wilschut and Pijls, 2018).

Furthermore, the starting point of the Robot Love Design-a-thon that preservice teachers should learn to work in interdisciplinary teams was unambiguously confirmed as a positive experience: all preservice teachers noted in the learner reports that working in mixed teams (disciplines, ages) was relevant and meaningful and allowed them to take on different, complementary roles that enriched the design process. Obtaining these kinds of interdisciplinary experiences is important as the ability to collaborate with colleagues from other subjects plays an important role in carrying out cross-curricular education (Wilschut and Pijls, 2018).

Taking a more critical stance, the findings also indicated that some aspects of the Design-a-thon could be improved. First of all, the preservice teachers without a background in the arts did not find the exhibition meaningful: the art works and theme were not accessible or appealing to them. When redesigning such a Designa-thon, all backgrounds of participating preservice teachers should be taken into account - for instance, in this study, a more extensive tour of the exhibition could have been given with explanations of the art works, making them more accessible.

Also, the preservice art teachers were especially critical about the curriculum materials which they found childish and not artistic enough. The materials were the same as used in a Design-a-thon for primary education - the idea being that the transfer of such materials to the classroom practice would be facilitated. A solution would be to provide the preservice teachers with materials at their 'own level' and to provide them with information about which materials could be used in primary and secondary education.

Furthermore, the observations made the team roles of the preservice teachers insightful: of all the preservice teachers, the preservice art teachers seemed to be able to question the problem ('How can technology promote tenderness between people?') and theme of the Design-a-thon in the most critical way. Yet at the same time, they could get stuck in their opinions, thus obstructing the interdisciplinary working process. These observations should, however, be interpreted with some caution as the preservice art teachers were in the majority and felt more at ease with the exhibition and its theme.

In conclusion, an ArtsSciences Design-a-thon seems to offer different entry points for preservice teachers to develop knowledge about and experience with pedagogical strategies and content for cross-curricular education. Working in interdisciplinary teams is a real advantage as teachers from other disciplines can offer new perspectives on problems. As such, ArtsSciences Design-a-thons in higher education can pave the way for innovative and thought-provoking education in primary and secondary schools. 


\section{ACKNOWLEDGEMENT}

This article draws on and extends ideas from the Dutch peer reviewed article Hotze, A., Bremmer, M., Heijnen, E., Pijls, M., Beamer, E. and Roos, N. (2019).

\section{REFERENCES}

Akkerman, S. F. and Bakker, A. (2011). Boundary crossing and boundary objects. Review of Educational Research, 81(2), p. 132-169. https://doi.org/10.3102/0034654311404435

Beamer Cronin, E. and Hyman, D. H. (2018) Where MakerEd meets Change-Maker ED. The journey to the classroom, in P. Troxler and R. Klapwijk (eds.), Proceedings of FabLearn Netherlands 2018 (pp. 34-42). Eindhoven: Fablearn Netherlands.

Beamer, E. (2017). Designathon. Praxisbulletin, 34(7), 84-87. https:// doi.org/10.5414/TEX01464

Berganton, M. (2017). Engaging with the SDGs: An interview with the Rector, Prof. Karen Maex. Available at: http://csds.uva.nl/content/

Bogers, L. and Chiappini, L. (Eds.) (2019). The critical makers reader: (Un)learning technology. Amsterdam, the Netherlands: Institute of Network Cultures. https://networkcultures.org/blog/publication/the-criticalmakers-reader-unlearning-technology/

Braun, V. and Clarke, V. (2006). Using thematic analysis in psychology. Qualitative Research in Psychology, 3(2), 77101. https:// doi.org/10.1191/1478088706qp063oa

Davies, M. and Devlin, M. (2010). Interdisciplinary higher education. In M. Davies, M. Devlin, and M. Tight (eds.), Interdisciplinary higher education: Perspectives and practicalities. International perspectives on higher education research, Vol. 5 (pp. 3-28). Bingley, UK: Emerald Group Publishing Limited. https://doi.org/10.1108/S14793628(2010)0000005004

De Greef, L. Post, G., Vink, C. and Wenting, L. (2017). Designing interdisciplinary education: A practical handbook for university teachers. Amsterdam, the Netherlands: Amsterdam University Press. https://doi.org/10.5117/9789462984769

De Groot, A. D. (1980). Overleerervaringen en leerdoelen [About Learning experiences and teaching goals] In Handboek voor de onderwijspraktijk: deel 2 (pp. 2.3 Gro. B1-18). Deventer, the Netherlands: Van Loghum Slaterus.

Flyvbjerg, B. (2006). Five misunderstandings about case study research. Qualitative Inquiry, 12(2), 219-245. https://doi.org/10.1177/1077800405284363

Gabrys, J. and Yusoff, K. (2012). Arts, sciences and climate change: Practices and politics at the threshold. Science as Culture, 21(1), 1-24. https:// doi.org/10.1080/09505431.2010.550139

Gess, A. H. (2017). STEAM education: Separating fact from fiction. Technology \& Engineering Teacher, 77(3), 39-41.

Groenendijk, T. and Heijnen, E. (2018). Trandisciplinaire ontwerplabs: Een ontwerponderzoek naar lesmateriaal op het snijvlak van kunst, wetenschap en technologie [Transdisciplinary design labs: a design research on teaching material at the intersection of art, science, and technology]. Amsterdam, the Netherlands: Amsterdam University of the Arts.

Heijnen, E., Bremmer, M., Groenendijk, T. and Koelink M. (2020). Arts laboratories and science studios: ArtsSciences collaboration in schools, in A. Knochel, C. Liao and R. Patton (eds.), Critical Digital Making (pp. 171-186). New York, NY: Peter Lang Publishing.

Heijnen, E. and Bremmer, M. (2019). ArtsSciences als aanjager van curriculumvernieuwing [How ArtsSciences can advance the innovation of the curriculum]. Cultuur + Educatie, 19(51), 8-18.

Heijnen, E. (2015). Remixing the Art Curriculum: How Contemporary Visual Practices Inspire Authentic Art Education. (Doctoral Dissertation). Radboud University Nijmegen, Nijmegen.

Hogenes, M., Diepenbroek, A., Bremmer, M. and Hogerheide, M. (2021). Designing new, technology based musical instruments in primary education. Journal of the European Teacher Education Network, 1-18.

Hotze, A., Bremmer, M., Heijnen, E., Pijls, M., Beamer, E. and Roos, N. (2019). ArtsSciences designathon. Pressure cooker voor aankomende leraren die vanuit verschillende disciplines samenwerken aan een vakoverstijgende ontwerptaak [Pressure cooker for preservice teachers working together on a transdisciplinary design task from various professional fields]. Velon, 40(3), 196-206.

Kraaij, D. A. (2015). Onderzoekend en ontwerpend leren. Wageningen, the Netherlands: Wetenschapsknooppunt Wageningen University.

Kim, D. and Bolger, M. (2017). Analysis of Korean elementary pre-service teachers' changing attitudes about integrated STEAM pedagogy through developing lesson plans. International Journal of Science and Mathematics Education, 15(4), 587-605. https:// doi.org/10.1007/s10763-015-9709-3

Lam, C. C. and Chan, K. S. J. (2011). How schools cope with a new integrated subject for senior secondary students: an example from Hong Kong. Curriculum Perspectives, 31(3), 23-32. 
Liao, C. (2016). From interdisciplinary to transdisciplinary: An arts-integrated approach to STEAM education. Art Education, 69(6), 44-49. https://doi.org/10.1080/00043125.2016.1224873

Marshall, J. (2014). Transdisciplinarity and art integration: Toward a new understanding of art-based learning across the curriculum. Studies in Art Education, 55(2), 104-127. https:/ / doi.org/10.1080/00393541.2014.11518922

Miller, A. I. (2014). Colliding worlds: How cutting-edge science is redefining contemporary art. New York, NY: W.W. Norton \& Company.

Ministry of Education, Culture, \& Science (2015). De waarde(n) van weten. Strategische Agenda Hoger Onderwijs en Onderzoek 2015-2025 [V alue and values of knowledge. A strategic agenda for higher education and research 2015-2025]. The Hague, the Netherlands: Ministerie van Onderwijs, Cultuur en Wetenschap.

Newell, W. H. (2007). Decision making in interdisciplinary studies. In G. Morçöl (ed.), Handbook of decision making (pp. 245-264). New York, NY: CRC Press. https://doi.org/10.1201/9781420016918.ch13

Newell, W. H. (2009). Interdisciplinarity in undergraduate general education. In R. Frodeman, J. T. Klein and C. Mitcham (eds.), The Oxford handbook on interdisciplinarity (pp. 360-371). Oxford, UK: Oxford University Press.

Pellegrino, J. W. and Hilton, M. L. (2012). Education for life and work: Developing transferable knowledge and skills in the 21st century. Washington D.C.: The National Academies Press.

Powell, R. R. (2006). Evaluation research: An overview. Library Trends, 55(1), 102-120. https://doi.org/10.1353/lib.2006.0050

Quigley, C. F. and Herro, D. (2016). 'Finding the joy in the unknown': Implementation of STEAM teaching practices in middle school science and math classrooms. Journal of Science Education and Technology, 25(3), 410-426. https://doi.org/10.1007/s10956-016-9602-z

Ratto, M. (2011). Critical Making: Conceptual and material studies in technology and social life. The Information Society: An International Journal, 27(4), 252-260. https:/ / doi.org/10.1080/01972243.2011.583819

Rinke, C. R., Gladstone-Brown, W., Kinlaw, C. R. and Cappiello, J. (2016). Characterizing STEM teacher education: Affordances and constraints of explicit STEM preparation for elementary teachers. School Science and Mathematics, 116(6), 300-309. https://doi.org/10.1111/ssm.12185

Rogers, Y., Scaife, M. and Rizzo, A. (2005). Interdisciplinarity: An emergent or engineered process? In S. Derry, C. Schunn and M. Gernsbacher (eds.), Interdisciplinary collaboration: An emerging cognitive science (pp. 265-285). Mahwah, NJ: Lawrence Erlbaum.

Root-Bernstein, B., Siler, T., Brown, A. and Snelson, K. (2011). Artscience: Integrative collaboration to create a sustainable future. Leonardo, 44(3), p. 192-192. https:// doi.org/10.1162/LEON_e_00161

Sanders, M. (2009). STEM, STEM Education, STEMmania. The Technology Teacher, 68(4), 20-26.

Squires, G. (1992). Interdisciplinarity in higher education in the United Kingdom. European Journal of Education, 27(3), 201-210. https:// doi.org/10.2307/1503449

Van Casteren, W., van Broek, A., Hölsgens, R. and Warps, J. (2014). Wetenschap en Technologie op de pabo's. Een inventarisatie van de stand van zaken 2013 [Science and technology at teacher training courses. A statement of affairs 2013]. Nijmegen, the Netherlands: ResearchNed.

Van Kesteren, B. J. (1993). Applications of De Groot's 'learner report': A tool to identify educational objectives and learning experiences. Studies in Educational Evaluation, 19(1), 65-86. https://doi.org/10.1016/S0191491X(05)80057-4

Van Merriëboer, J. J. G. (2013). Perspectives on problem solving and instruction. Computers and Education, 64, 153160. https://doi.org/10.1016/j.compedu.2012.11.025

Zwijnenberg R. (2013). On the need for cooperation between art and science. In J. Thissen, R., Zwijnenberg and K. Zijlmans (eds.), Contemporary culture. New directions in art and bumanities research (pp. 169-174). Amsterdam, the Netherlands: Amsterdam University Press. https:/ / doi.org/10.1515/9789048517954-013 